\title{
Application of Bradford's Law of Scattering to the Physics Literature: A Study of Doctoral Theses Citations at the Indian Institute of Science
}

\author{
K.G. Sudhier \\ Department of Library\& Information Science \\ University of Kerala, University Library Building \\ Thiruvananthapuram-695 034, Kerala \\ E-mail:kgsudhier@gmail.com
}

\begin{abstract}
One of the areas in bibliometric research concerns the application of most commonly used bibliometric laws such as Bradford's Law of Scattering. The paper gives a review of the scholarly contribution on the various facets of Bradford's Law. In addition to the theoretical aspects of the law, review covers papers dealing with the application of the law in the various subject fields. A study on five-year data of journals (2004-2008) cited by the physicists at the Indian Institute of Science (IISc), Bangaluru was carried out to examine the applicability of Bradford's Law of Scattering, which include 690 periodicals containing 11,319 references collected from 79 doctoral theses during the period 2004-08. Ranked list of journals was prepared, and Physical Review-B with 9.53 per cent citation, followed by Physical Review-A with 7.69 per cent, and Astrophysical Journal with 5.47 per cent citations were the most preferred journals. Applicability of Bradford's Law in various methods was tested. The journal distribution pattern of the IISc doctoral theses does not fit the Bradford's distribution pattern. The Bradford multipliers were calculated, and the law found to be applicable with the value of $\mathrm{k}$ as 1.2. The distribution of the journals in three zones was made and the number of references in each zone was then estimated. The applicability of Leimkuhler model was also tested with the present data.
\end{abstract}

Keywords: Bradford's law of scattering, Bradford's multiplier, physics literature, journal citations, core journals, Indian Institute of Science

\section{INTRODUCTION}

In every subject there are some journals which are frequently referred by the researchers because of the close relation between the subject of the journals and the areas of research work. These highly cited journals are listed as core journals of the specific subject. The core journals are considered as 'central set of journals, which most clearly reflects the conceptual essence of the research being reported in the discipline'1. The core journals always contain a higher concentration of relevant articles in a particular discipline.

The concept of core journals is derived from Bradford's Law of Scattering, which was formulated by Samuel Clement Bradford in 1934. Bradford ${ }^{2}$ first published his observation of the increasing scatter of relevant journal articles on a given topic, and later in 1948, summarised these observations by relating the number of journals in the nuclear, or most productive zone, to the number of journals in successively less productive zones containing equal numbers of papers ${ }^{3}$. Among the several statistical expressions, Bradford's Law of Scattering is perhaps the most popular and the best known of all the bibliometric concepts that try to describe the effective working of science by mathematical means ${ }^{4}$.

\section{PREVIOUS STUDIES}

Bradford's Law of scattering has been the main topic of many articles in LIS literature. The discussions of the law take several directions: analysis of the law itself, attempts to refine it, comparison with other laws, and its applications.

The first notable paper on the law was by Vickery ${ }^{5}$ and subsequently by Kendall6. The bipolar nature of the law was further discussed by Wilkinson? ${ }^{7}$. He suggested that the verbal formulation expressed Bradford's theory, 
while the graphical formulation expressed his observations. The search for an exact formulation of Bradford's Law was stated by Vickery and Leimkuhler ${ }^{8}$ and was further pursued by many other authors. In 1977 , Brookes $^{9}$ contributed his theory of Bradford's law in the commemorative issue of the Journal of Documentation. In this classic paper, Brookes did a complete evaluation of the Bradford's Law and concluded, "Bradford was therefore a pioneer in social mathematics". Avramescu ${ }^{10}$ gave the theoretical foundation of the law. A comprehensive review of the mathematical evolution of Bradford's Law was done by Oluic-Vukovic. ${ }^{11}$ Locket $^{12}$ reviewed the significant studies. An empirical examination of the Law was done by $\mathrm{Qiu}^{13}$. The gap between empirical and theoretical considerations of the phenomenon described by Bradford's law has been pointed out by Drott ${ }^{14}$.

Different authors have given many alternative models derived for scattering. Groos ${ }^{15}$ observed a S-shaped curve (with a droop, at the end of the curve) to explain law of scattering. Fairthorne ${ }^{16}$ and Asai ${ }^{17}$ suggested a log model. The dual of Bradford Law was proposed by Egghe $^{18}$. Burrel ${ }^{19}$ suggested warring process to explain general features of Bradford' law. Basu ${ }^{20}$ suggested that the Bradford' regularity acquires two pairs of description, Bradford's verbal law (sequence of ratios) and the classic Leimkuhler law (equation); Bradford's graphical law (plotted graphs) and Brooke' law (equation). Again she suggested a model to explain distribution of articles in journals based on probabilistic considerations ${ }^{21}$.

The theory of Bradford Law to the calculation of Leimkuhler Law was proposed by Egghe. ${ }^{22} \mathrm{He}$ also gave a note on different Bradford multipliers. ${ }^{23}$ To identify a suitable model to explain the law of scattering, Ravichandra $\mathrm{RaO}^{24}$ fitted about 24 different models to the 12 different sets of data. He observed that log-normal model fits much better than many other models, including the log-linear model. Wagner-Dobber ${ }^{25}$ have also made their comments on the Law. Recently, Nicolaisen and Hjorland ${ }^{26}$ in their article presented practical potentials of Bradford Law.

A number of studies were carried out to verify the authenticity of the Bradford's law. On the application side, the studies of Sengupta, ${ }^{27}$ and Goffman and Morris $^{28}$ are significant. The applicability of the two vital formulations (verbal and graphical) of Bradford's law of Scattering was tested by Arjun Lal and Panda ${ }^{29}$. The data were collected from 20 doctoral theses in plant Pathology submitted to Rajendra Agricultural University, Bihar, during 1980-93. Gupta ${ }^{30}$ studied the applicability of Bradford's law to citation data in Ethiopian Medical Journal. Other studies include, Lawani ${ }^{31}$ in Agriculture, Tyagi ${ }^{32}$ in Physics, Nweke ${ }^{33}$ in Zoology, Asundi and Kabir $^{34}$ in Horticulture, Bandyopadhyay ${ }^{35}$ in different disciplines, Sukla and Saksena ${ }^{36}$ in Bioenergy, and
Gupta and Suresh Kumar $^{37}$ in theoretical population genetics. The Law has been applied to study not only the scattering of publications, but in other sphere of activities also. A study conducted by Garg and Lalitha Sharma ${ }^{38}$ of R\&D indicators in Indian industry using Bradford's Law bears testimony to this fact.

Many scholars have studied the application of Bradford's Law in the distribution of publications in journals, coverage in international indexing and abstracting services, etc., but few have analysed the applicability of Bradford's Law in the distribution of journal citations in a particular institution. Hence, this study on the journals cited by the physicist of IISc in their doctoral theses becomes significant. IISc is the premier S\&T research institute in the country, where research in all the major areas of physics is being carried out. IISc celebrated its centenary in 2008.

\section{OBJECTIVES OF THE STUDY}

The main objectives of the study were:

(i) To prepare a rank list of most cited journals by the IISc physicists.

(ii) To study the phenomenon of scattering for citation data.

(iii) To test the appropriateness of verbal and graphical formulation of Bradford's Law of Scattering.

\section{METHODOLOGY}

A total of 690 journals containing 11,319 references collected from 79 doctoral theses were arranged in descending order of productivity. The study treated references as items and journals as sources. The verbal formulation was tested by three separate parameters for carrying the different number of periodicals, while for testing the appropriateness of graphical formulation, the natural log value of the cumulative number of journals was calculated for plotting the graph.

\subsection{Bradford's Law of Scattering}

Bradford's Law of Scattering describes a quantitative relation between journals and the papers these publish. Samuel Clement Bradford, Chief Librarian at the London Science Museum, made statistical analysis of two geophysics bibliographies, the Current Bibliography of Applied Geophysics (1928-1931) and the Quarterly Bibliography of Lubrication (1931-1933) ${ }^{2}$. He tested the journals containing references to these fields in their descending order of productivity and then divided the articles into three approximately equal zones or groups. He termed the first one as the nuclear zone, which is highly productive; the second zone as moderately productive zone; and the third zone as peripheral zone or low productive zone. Bradford discovered regularity in 
calculating the number of titles in each of the three zones. On the basis of the observations, Bradford concluded that the ratio of the titles of journals in successive zones followed a common pattern. Bradford's verbal formulation stated that if scientific journals are arranged in order of their decreasing productivity of articles on a given subject, they may be divided into a nucleus of periodicals more particularly devoted to the subject, and several 'groups' or 'zones' containing the same number of articles as the nucleus, where the number of periodicals in the nucleus and succeeding zones will be $1: n: n^{2}$, where ' $n$ ' is a multiplier ${ }^{3}$.

Based on Bradford's observations, Brookes ${ }^{39}$ suggested the following linear relation to describe the scattering phenomenon as:

$$
F(x)=a+b \log x
$$

where $F(x)$ is the cumulative number of references contained in the first $x$ most productive journals, and $a$ and $b$ are constants. This is the most widely used formulation of Bradford's Law.

Vickery extended the verbal formulation to show that it can be applied to any number of zones of equal yield. Leimkuhler $^{8}$ issued the following simple function for Bradford' distribution, which was named after him:

$$
R(r)=a \log (1+b r)
$$

where $R(r)$ is the cumulative number of articles contributed by journals ranked 1 through $r$, and $a$ and $b$ are parameters.

Similarly, Brookes derivation for journal productivity takes the form

$$
R(r)=a \log (b / r)
$$

Further, Wilkinson ${ }^{7}$ noticed that the formulae provided by Leimkuhler and Brookes did not really describe the same phenomenon. Starting from the late 1960s, several mathematical formulations, models, and syntheses of previous statements related to Bradford's Law have been put forth, but very little agreement exists about which model is the best. Brookes expression of the Bradford distribution has however gained wide acceptance.

\subsection{Theoretical Aspects of Bradford's Law}

Bradford's Law of Scattering describes a quantitative relationship between journals and the papers they publish. It explains that, only a small number of core journals will supply the nucleus of papers on a given topic which accounts for a substantial percentage (1/3) of the articles, to be followed by a second larger group of journals that accounts for another third, while a much larger group of journals picked up the last third ${ }^{3}$.

There are two most widely recognised formulations of the so called Bradford's Law: the verbal formulation which is derived from the verbal statement of Bradford's conclusion, and the graphical formulation, which is an empirical expression derived from the graphical survey of a distribution of periodicals ${ }^{40}$.

Bradford did not give a mathematical model for his law. Models were suggested later by Brookes, Vickery and Leimkuhler. Several authors, while explaining the scattering of articles in journals, have formulated many different models of Bradford's Law. Leimkuhler developed a model based on Bradford's verbal formulation as ${ }^{41}$ :

$$
\begin{aligned}
& R(r)=a \log (1+b r) \\
& r=1,2,3 \ldots
\end{aligned}
$$

while explaining Leimkuhler's Law, Egghe shows that

$$
\begin{aligned}
& a=Y_{0} / \log k \\
& b=k-1 / r_{0}
\end{aligned}
$$

where $r_{0}$ is the number of sources in the first Bradford group, $Y_{0}$ the number of items in every Bradford group (all these group of item being of equal sizes), and $k$ the Bradford multiplier.

$R(r)$ is the cumulative number of items produced by the sources of rank $1,2,3 \ldots r$ and $a$ and $b$ are constants appearing in the law of Leimkuhler. In forming Bradford groups, it is shown that the number of groups $p$ is a parameter that can be chosen freely.

Egghe $^{22}$ has shown the mathematical formula for calculating the Bradford Multiplier $k$ as

$$
k=\left(e^{\gamma} y_{m}\right)^{1 / p}
$$

where $g$ is Euler's number $\left(\mathrm{e}^{g}=1.781\right)$.

If the sources are ranked in decreasing order of productivity, then $y_{m}$ is the number of items in the most productivity sources.

$$
\begin{aligned}
& \text { Then } y_{0} \text { and } r_{0} \text { are: } \\
& Y_{0}=y_{m}^{2} \log k \text { and } \\
& r_{0}=(k-1) Y_{m}
\end{aligned}
$$

Once $p$ is chosen, the value of $k$ can be calculated by using 


$$
k=\left(1.781 y_{m}\right)^{1 / p}
$$

and $Y_{0}=A / P$

where $A$ denotes the total number of articles.

Let $\mathrm{T}$ denote the total number of journals in Bradford group, there are $r_{0} k^{i-1}$ sources $(i=1,2,3 \ldots \ldots p)$

$$
\begin{aligned}
& T=r_{0}+r_{0} k+r_{0} k^{2}+\ldots \ldots \ldots+r_{0} k^{p-2} \\
& \text { So, } r_{0}=T / 1+k+k^{2}+\ldots \ldots \ldots \ldots+k^{p-1}=T(k-1) /\left(k^{p}-1\right)
\end{aligned}
$$

Since $A$ and $T$ are known from the data set, $r_{0}$ and $Y_{0}$ are calculated, once $p$ is calculated by the formula (7)

Gupta and Suresh Kumar ${ }^{37}$ have given the theoretical aspects of Bradford's Law and studied its applicability using the above method. According to Brookes ${ }^{42}$, to test the conformity of Bradford's law, one should meet the following three implicit conditions:

(i) In dividing the journals into zones, the number of articles in each zone must remain constant.

(ii) The Bradford multiplier $k$ must be $>1$.

(iii) The Bradford multiplier must remain approximately constant.

\section{ANALYSIS AND DISCUSSION}

\subsection{Top-ranked Journals}

Core journals ranking studies are usually made to help in the selection of journals and in assessing the importance of one or more journals in a particular subject field. The journals are arranged in their respective descending order of frequency and in alphabetical order among the same rank number. The journal contributing the largest number of articles is ranked as number one, next is ranked two and so on. The criterion for ranking is purely quantitative not qualitative.

The ranked list of most cited journals of IISc are shown in the Table 1. In the analysis, the citation of articles is distributed in 690 journals with a total of 11,412 citations. From the Table 1 it is clear that Physical Review $B$, a specialised journal in the area of Condensed Matter Physics published by American Physical Society (APS) tops the list with the highest contribution of 1087 (9.53 per cent) citations. Physical Review $A$, also a publication of APS, is in the second position by accounting 878 (7.69 per cent) articles, while Astrophysical Journal, published from USA by University of Chicago Press occupies the third position with 624 (5.47 per cent) citations. Of the journals of IISc, 51 journals are cited at least 37 times or more. The most cited journals are usually well established and known worldwide. With more available to be cited more often than newer journals. Majority of the most cited journals of IISc are being published for about or more than 100 years. Physical Review B (110 Years), Physical Review A (110 Years), Astrophysical Journal (108 Years), Nature (134 Years), etc.

Among the journals listed in the Table 1, some journals include the word 'letters' or 'communication' in their titles. These journals are letters or communication type, such as Physical review Letters, Applied Physics Letters, Solid State Communication, Physics Review letters etc. The purpose of this preliminary communication is to establish priority for an invention and to disseminate nascent information on current research in the scientific community. Nature and Science, though they are not letters journals, their main purpose is reporting preliminary communication and current research. In general, these journals publish short articles with a short time interval and most of them are weekly or biweekly publications. With more new information to be cited, it is not surprising that these journals are receiving more citations than the general journals, as seen in the IISc ranked journal list ${ }^{43}$. The next remarkable feature of the study is the high status of multi-disciplinary science journals in the core journals list of Physics literature. It is evident from the analysis that Nature, Current Science, Science, Proc. Indian Academy of Science, Proc. Nati. Acad.; Sci. Proc. Roy. Soc. London, etc. are in the top ranks in IISc theses.

The top ranked journals of IISc researchers indicate that 8 out of the first 10 journals are published from USA. It is also interesting to see that out of the top 10 journals, 4 journals are published by American Institute of Physics (AIP) and 3 journals are by American Physical Society (APS). The prestigious science journal Nature published by the Nature publishing group of United Kingdom is in the 9th position with 223 (1.95 per cent) citations.

\subsection{Application of Bradford' Law}

To observe the appropriateness of the distribution of journals using the verbal formulation of Bradford Law, the following explanations are made and the results presented. The first part deals with the verbal formulation of the theory based on data consisting whole periodical references, arranged by their decreasing frequency of citations while the second part examines the graphical representations based on the same data.

\subsubsection{Verbal Formulation}

Table 2 presents several details of journal citations to test the verbal formulation of Bradford's law. The number of cited journals has been arranged by decreasing number of citations To test the verbal formulation of Bradford's law, the. Rank, no. of journals, 
Table 1. Ranked list of journals

\begin{tabular}{|c|c|c|c|c|c|c|c|}
\hline S. $\mathbf{N}$. & Journals & Year & Country & Publisher & Rank & Count & $\%$ \\
\hline 1 & Physics Review B & 1893 & USA & APS & 1 & 1087 & 9.53 \\
\hline 2 & Physics Review A & 1893 & USA & APS & 2 & 878 & 7.69 \\
\hline 3 & Astrophysical Journal & 1895 & USA & UCP & 3 & 624 & 5.47 \\
\hline 4 & Physics Review Letter & 1958 & USA & APS & 4 & 583 & 5.11 \\
\hline 5 & Journal Chemical Physics & 1931 & USA & AIP & 5 & 369 & 3.23 \\
\hline 6 & Physics Review D & 1991 & USA & AIP & 6 & 318 & 2.79 \\
\hline 7 & Applied Physics Letter & 1962 & USA & AIP & 7 & 269 & 2.36 \\
\hline 8 & Astronomy \& Astrophysics & 1930 & France & EDP Sci. & 8 & 252 & 2.21 \\
\hline 9 & Nature & 1869 & UK & Nature Pub. & 9 & 223 & 1.95 \\
\hline 10 & Journal Applied Physics & 1931 & USA & AIP & 10 & 212 & 1.86 \\
\hline 11 & $\begin{array}{l}\text { Journal Crystallagraphy } \\
\text { Growth }\end{array}$ & 1967 & Netherlands & Elsevier & 11 & 189 & 1.66 \\
\hline 12 & $\begin{array}{l}\text { Monthly Journal of Royal } \\
\text { A stronomical Society }\end{array}$ & 1827 & UK & Blackwell & 12 & 184 & 1.61 \\
\hline 13 & Acta Crystallography & 1948 & Denmark & Blackwell & 13 & 167 & 1.46 \\
\hline 14 & $\begin{array}{l}\text { Journal American Chemical } \\
\text { Society }\end{array}$ & 1879 & USA & ACS & 14 & 155 & 1.36 \\
\hline 15 & Solid State Communication & 1963 & USA & Pergamon & 15 & 148 & 1.30 \\
\hline 16 & Science & 1880 & USA & AAAS & 16 & 144 & 1.26 \\
\hline 17 & Physica C & 1934 & Netherlands & Elsevier & 17 & 142 & 1.24 \\
\hline 18 & J.Non-Crystalline solids & 1969 & Netherlands & Elsevier & 18 & 127 & 1.11 \\
\hline 19 & Journal Molecular Biololgy & 1959 & USA & Academic & 19 & 126 & 1.10 \\
\hline 20 & Review Modern Physics & 1929 & USA & APS & 20 & 125 & 1.10 \\
\hline 21 & Biopolymers & 1961 & USA & $\begin{array}{l}\text { John } \\
\text { Wiley }\end{array}$ & 21 & 121 & 1.06 \\
\hline 22 & Journal Magnetic Resonance & 1969 & USA & Academic & 22 & 116 & 1.02 \\
\hline 23 & $\begin{array}{l}\text { Journal Physics Chemical } \\
\text { Solids }\end{array}$ & 1956 & USA & Pergamon & 23 & 108 & 0.95 \\
\hline 24 & $\begin{array}{l}\text { Journal Physics Condensed } \\
\text { Matter }\end{array}$ & 1968 & UK & IOP & 24 & 103 & 0.90 \\
\hline 25 & Chemical Physics Letter & 1967 & Netherlands & Elsevier & 25 & 98 & 0.86 \\
\hline 26 & Europhysics Letter & 1986 & France & EDP Sci. & 26 & 96 & 0.84 \\
\hline 27 & Astronomical Journal & 1849 & US & UCP & 27 & 84 & 0.74 \\
\hline 28 & Journal Peptide Resonance & 1997 & Denmark & Blackwell & 28 & 83 & 0.73 \\
\hline 29 & Philosophical Magazine & 1908 & UK & $\begin{array}{l}\text { Taylor \& } \\
\text { Francis }\end{array}$ & 29 & 79 & 0.69 \\
\hline 30 & Solar Physics & 1967 & Netherlands & Springer & 30 & 78 & 0.68 \\
\hline
\end{tabular}


Table 2. Citations and citing journals used by researchers at IISc

\begin{tabular}{|c|c|c|c|c|c|c|c|c|}
\hline \multirow{2}{*}{$\begin{array}{c}\text { Rank } \\
1 \\
1\end{array}$} & \multirow{2}{*}{$\begin{array}{c}\text { No. Jls } \\
1\end{array}$} & \multirow{2}{*}{$\begin{array}{c}\begin{array}{c}\text { Cum. No. of } \\
\text { Jls }\end{array} \\
1\end{array}$} & \multirow{2}{*}{$\begin{array}{c}\text { No. Cits } \\
1087\end{array}$} & \multicolumn{2}{|c|}{ Tot No. Cits Cum. of Cits } & \multirow{2}{*}{$\begin{array}{c}\log (n) \\
0.00\end{array}$} & \multirow{2}{*}{$\begin{array}{c}\begin{array}{c}\% \\
\text { of Cits }\end{array} \\
9.60\end{array}$} & \multirow{2}{*}{$\begin{array}{c}\% \text { of Tot Jls. } \\
0.14\end{array}$} \\
\hline & & & & 1087 & 1087 & & & \\
\hline 2 & 1 & 2 & 878 & 878 & 1965 & 0.69 & 17.36 & 0.29 \\
\hline 3 & 1 & 3 & 624 & 624 & 2589 & 1.10 & 22.87 & 0.43 \\
\hline 4 & 1 & 4 & 583 & 583 & 3172 & 1.39 & 28.02 & 0.58 \\
\hline 5 & 1 & 5 & 369 & 369 & 3541 & 1.61 & 31.28 & 0.72 \\
\hline 6 & 1 & 6 & 318 & 318 & 3859 & 1.79 & 34.09 & 0.87 \\
\hline 7 & 1 & 7 & 269 & 269 & 4128 & 1.95 & 36.47 & 1.01 \\
\hline 8 & 1 & 8 & 252 & 252 & 4380 & 2.08 & 38.70 & 1.16 \\
\hline 9 & 1 & 9 & 223 & 223 & 4603 & 2.20 & 40.67 & 1.30 \\
\hline 10 & 1 & 10 & 212 & 212 & 4815 & 2.30 & 42.54 & 1.45 \\
\hline 11 & 1 & 11 & 189 & 189 & 5004 & 2.40 & 44.21 & 1.59 \\
\hline 12 & 1 & 12 & 184 & 184 & 5188 & 2.48 & 45.83 & 1.74 \\
\hline 13 & 1 & 13 & 167 & 167 & 5355 & 2.56 & 47.31 & 1.88 \\
\hline 14 & 1 & 14 & 155 & 155 & 5510 & 2.64 & 48.68 & 2.03 \\
\hline 15 & 1 & 15 & 148 & 148 & 5658 & 2.71 & 49.99 & 2.17 \\
\hline 16 & 1 & 16 & 144 & 144 & 5802 & 2.77 & 51.26 & 2.32 \\
\hline 17 & 1 & 17 & 142 & 142 & 5944 & 2.83 & 52.51 & 2.46 \\
\hline 18 & 1 & 18 & 127 & 127 & 6071 & 2.89 & 53.64 & 2.61 \\
\hline 19 & 1 & 19 & 126 & 126 & 6197 & 2.94 & 54.75 & 2.75 \\
\hline 20 & 1 & 20 & 125 & 125 & 6322 & 3.00 & 55.85 & 2.90 \\
\hline 21 & 1 & 21 & 121 & 121 & 6443 & 3.04 & 56.92 & 3.04 \\
\hline 22 & 1 & 22 & 116 & 116 & 6559 & 3.09 & 57.95 & 3.19 \\
\hline 23 & 1 & 23 & 108 & 108 & 6667 & 3.14 & 58.90 & 3.33 \\
\hline 24 & 1 & 24 & 103 & 103 & 6770 & 3.18 & 59.81 & 3.48 \\
\hline 25 & 1 & 25 & 98 & 98 & 6868 & 3.22 & 60.68 & 3.62 \\
\hline 26 & 1 & 26 & 96 & 96 & 6964 & 3.26 & 61.52 & 3.77 \\
\hline 27 & 1 & 27 & 84 & 84 & 7048 & 3.30 & 62.27 & 3.91 \\
\hline 28 & 1 & 28 & 83 & 83 & 7131 & 3.33 & 63.00 & 4.06 \\
\hline 29 & 1 & 29 & 79 & 79 & 7210 & 3.37 & 63.70 & 4.20 \\
\hline 30 & 1 & 30 & 78 & 78 & 7288 & 3.40 & 64.39 & 4.35 \\
\hline 31 & 1 & 31 & 73 & 73 & 7361 & 3.43 & 65.03 & 4.49 \\
\hline 32 & 1 & 32 & 67 & 67 & 7428 & 3.47 & 65.62 & 4.64 \\
\hline 33 & 1 & 33 & 61 & 61 & 7489 & 3.50 & 66.16 & 4.78 \\
\hline 34 & 2 & 35 & 60 & 120 & 7609 & 3.56 & 67.22 & 5.07 \\
\hline
\end{tabular}




\begin{tabular}{|c|c|c|c|c|c|c|c|c|}
\hline Rank & No. Jls & Cum. No. of & No. Cits & Tot No. Cits & Cum. of Cits & $\log (n)$ & $\%$ & $\%$ of \\
\hline 35 & 1 & 36 & 53 & 53 & 7662 & 3.58 & 67.69 & 5.22 \\
\hline 36 & 1 & 37 & 52 & 52 & 7714 & 3.61 & 68.15 & 5.36 \\
\hline 37 & 1 & 38 & 50 & 50 & 7764 & 3.64 & 68.59 & 5.51 \\
\hline 38 & 2 & 40 & 49 & 98 & 7862 & 3.69 & 69.46 & 5.80 \\
\hline 39 & 1 & 41 & 48 & 48 & 7910 & 3.71 & 69.88 & 5.94 \\
\hline 40 & 1 & 42 & 47 & 47 & 7957 & 3.74 & 70.30 & 6.09 \\
\hline 41 & 1 & 43 & 46 & 46 & 8003 & 3.76 & 70.70 & 6.23 \\
\hline 42 & 3 & 46 & 45 & 135 & 8138 & 3.83 & 71.90 & 6.67 \\
\hline 43 & 1 & 47 & 44 & 44 & 8182 & 3.85 & 72.29 & 6.81 \\
\hline 44 & 1 & 48 & 40 & 40 & 8222 & 3.87 & 72.64 & 6.96 \\
\hline 45 & 1 & 49 & 38 & 38 & 8260 & 3.89 & 72.97 & 7.10 \\
\hline 46 & 2 & 51 & 37 & 74 & 8334 & 3.93 & 73.63 & 7.39 \\
\hline 47 & 3 & 54 & 36 & 108 & 8442 & 3.99 & 74.58 & 7.83 \\
\hline 48 & 2 & 56 & 34 & 68 & 8510 & 4.03 & 75.18 & 8.12 \\
\hline 49 & 1 & 57 & 33 & 33 & 8543 & 4.04 & 75.47 & 8.26 \\
\hline 50 & 2 & 59 & 32 & 64 & 8607 & 4.08 & 76.04 & 8.55 \\
\hline 51 & 1 & 60 & 31 & 31 & 8638 & 4.09 & 76.31 & 8.70 \\
\hline 52 & 1 & 61 & 30 & 30 & 8668 & 4.11 & 76.58 & 8.84 \\
\hline 53 & 3 & 64 & 29 & 87 & 8755 & 4.16 & 77.35 & 9.28 \\
\hline 54 & 1 & 65 & 28 & 28 & 8783 & 4.17 & 77.60 & 9.42 \\
\hline 55 & 3 & 68 & 26 & 78 & 8861 & 4.22 & 78.28 & 9.86 \\
\hline 56 & 6 & 74 & 25 & 150 & 9011 & 4.30 & 79.61 & 10.72 \\
\hline 57 & 1 & 75 & 24 & 24 & 9035 & 4.32 & 79.82 & 10.87 \\
\hline 58 & 3 & 78 & 23 & 69 & 9104 & 4.36 & 80.43 & 11.30 \\
\hline 59 & 1 & 79 & 22 & 22 & 9126 & 4.37 & 80.63 & 11.45 \\
\hline 60 & 2 & 81 & 21 & 42 & 9168 & 4.39 & 81.00 & 11.74 \\
\hline 61 & 4 & 85 & 20 & 80 & 9248 & 4.44 & 81.70 & 12.32 \\
\hline 62 & 5 & 90 & 19 & 95 & 9343 & 4.50 & 82.54 & 13.04 \\
\hline 63 & 6 & 96 & 18 & 108 & 9451 & 4.56 & 83.50 & 13.91 \\
\hline 64 & 3 & 99 & 17 & 51 & 9502 & 4.60 & 83.95 & 14.35 \\
\hline 65 & 3 & 102 & 16 & 48 & 9550 & 4.62 & 84.37 & 14.78 \\
\hline 66 & 6 & 108 & 15 & 90 & 9640 & 4.68 & 85.17 & 15.65 \\
\hline 67 & 5 & 113 & 14 & 70 & 9710 & 4.73 & 85.78 & 16.38 \\
\hline 68 & 3 & 116 & 13 & 39 & 9749 & 4.75 & 86.13 & 16.81 \\
\hline 69 & 7 & 123 & 12 & 84 & 9833 & 4.81 & 86.87 & 17.83 \\
\hline 70 & 5 & 128 & 11 & 55 & 9888 & 4.85 & 87.36 & 18.55 \\
\hline
\end{tabular}




\begin{tabular}{cccccccccc}
\hline Rank & No. Jls & $\begin{array}{c}\text { Cum. } \\
\text { No.Jls }\end{array}$ & No. Cits & Tot No. Cits Cum. of Cits & log (n) & $\begin{array}{c}\% \\
\text { of Cits }\end{array}$ & of Tot Jls. \\
\hline 71 & 11 & 139 & 10 & 110 & 9998 & 4.93 & 88.33 & 20.14 \\
72 & 10 & 149 & 9 & 90 & 10088 & 5.00 & 89.12 & 21.59 \\
73 & 19 & 168 & 8 & 152 & 10240 & 5.12 & 90.47 & 24.35 \\
74 & 16 & 184 & 7 & 112 & 10352 & 5.21 & 91.46 & 26.67 \\
75 & 16 & 200 & 6 & 96 & 10448 & 5.30 & 92.30 & 28.99 \\
76 & 21 & 221 & 5 & 105 & 10553 & 5.40 & 93.23 & 32.03 \\
77 & 44 & 265 & 4 & 176 & 10729 & 5.58 & 94.79 & 38.41 \\
78 & 36 & 301 & 3 & 108 & 10837 & 5.71 & 95.74 & 43.62 \\
79 & 93 & 394 & 2 & 186 & 11023 & 5.98 & 97.38 & 57.10 \\
80 & 296 & 690 & 1 & 296 & 11319 & 6.54 & 100.00 & 100.00 \\
\hline
\end{tabular}

no. of citations, cumulative citations, log of cumulative citations are given in the Table 2.

For testing the algebraic interpretation of the Law, the 690 journal titles were divided into three zones. The Bradford's multiplier factor was arrived at by dividing periodical titles of a zone by its preceding zone. Bradford multiplier is expressed as the ratio of the number of periodical titles in any group to the number of periodical titles in any immediately preceding group. The basis for choosing the three zones was that the percentage error in distribution of citations, among the three zones should be minimum.

The distribution of journals and corresponding number of citations in the three zones along with the value of Bradford multipliers are shown in the Table 3.

In the present data set, 6 journals covered 3859 articles, next 30 journals covered 3803 articles and next 654 journals covered 3657 articles. In other words, one third of the total citations has been covered by each group of the journals.

According to Bradford, the zones, thus identified will form an approximately geometric series in the form $1: n$ $: n^{2}$. But it is found that the relationship of each zone in the present study is $6: 30: 654$. This does not fit into the Bradford's distribution.

Here, 6 represent the number of periodicals in the nucleus and $n=13.4$ is a multiplier. The mean value of multiplier is 13.4 .

Therefore, $6: 6 \times 13.4: 6 \times 13.4^{2}:: 1: \mathrm{n}: \mathrm{n}^{2}$

$6: 80.4: 1077.36$ » 1163.76

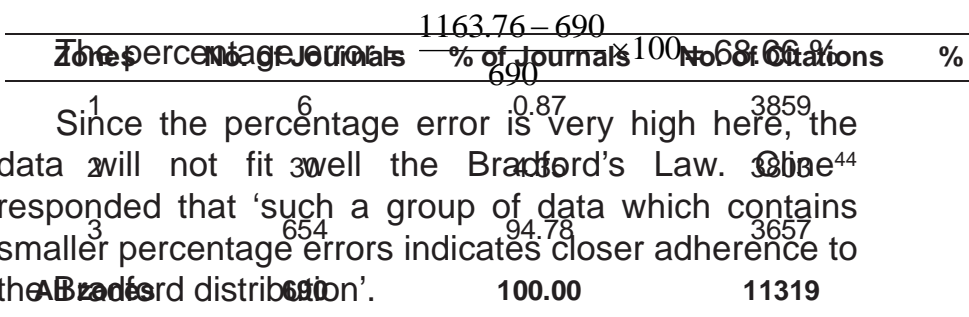

Therefore the Bradford's Law can be extended for the present data as:

$$
6: 6 \times 5: 6 \times 5^{2} \times 4.35 \gg 6: 30: 652.5
$$

when $5=n$, then $1: n: 4.35 n^{2}$

But here also, the multiplication constant 5 is calculated for the first two zones only, and the mean

Table 3. Scattering of journals and citations over Bradford zone 
value of multiplier (Table 3 ) is not fit well as discussed earlier. The modification is logically not correct and it will not serve the purpose what Bradford advocated.

Therefore, the following method based on the Leimkuhler model is employed for the verification of Bradford's law of Scattering.

\subsubsection{Application of Leimkuhler Model}

For application of Bradford's law, divide the citation distribution in three or more approximately equal zones $(p)$. Since Bradford assumes that there should be minimum 3 zones, here also $p$ is assumed to be 3 . Then by using the mathematical formula (4), the value of the Bradford's multiplier $\mathrm{k}$ is calculated as

$$
\begin{aligned}
& k=\left(1.781 \times Y_{m}\right)^{1 / p} \\
& =(1.781 \times 1087)^{1 / 3}=12.46 » 12 \\
& Y_{0}=A / p=11.319 / 3=3773 \\
& r_{0}=T(k-1) /\left(k^{p}-1\right)=690(12-1) /\left(12^{3}-1\right)=4.39 » 4
\end{aligned}
$$

$$
\begin{aligned}
& a=Y_{0} / \log k=3773 / \log 12=3496 \\
& b=k-1 / r_{0}=12-1 / 4=2.75 » 3
\end{aligned}
$$
Table 4.

The findings of the calculations are shown in the

Table 4 shows that the number of journals in the nucleus is 4 and the mean value of the Bradford multiplier is 12.60. Therefore, the Bradford's distribution is written as:

$$
\begin{aligned}
& 4: 4 \times 12.60: 4 \times(12.60)^{2} » 1: n: n^{2} \\
& \text { i.e., } 4: 50.4: 635.1 » 689.5
\end{aligned}
$$

\begin{tabular}{|c|c|c|c|}
\hline Zone & No. of Journals & $\%$ of Journals & No. of Citations \\
\hline 1 & 4 & 0.58 & 3172 \\
\hline 2 & 51 & 7.39 & 5162 \\
\hline
\end{tabular}$$
\text { Percentage of error }=\frac{689.5-690}{690} \times 100=0.072 \%
$$

Here the percentage error is negligible. It is also observed that, the number of periodicals contributing references to each zone increases by a multiplier of 12.60. The data of the zonal analysis shows that the

Table 4. Scattering of journals and citations over Bradford zones

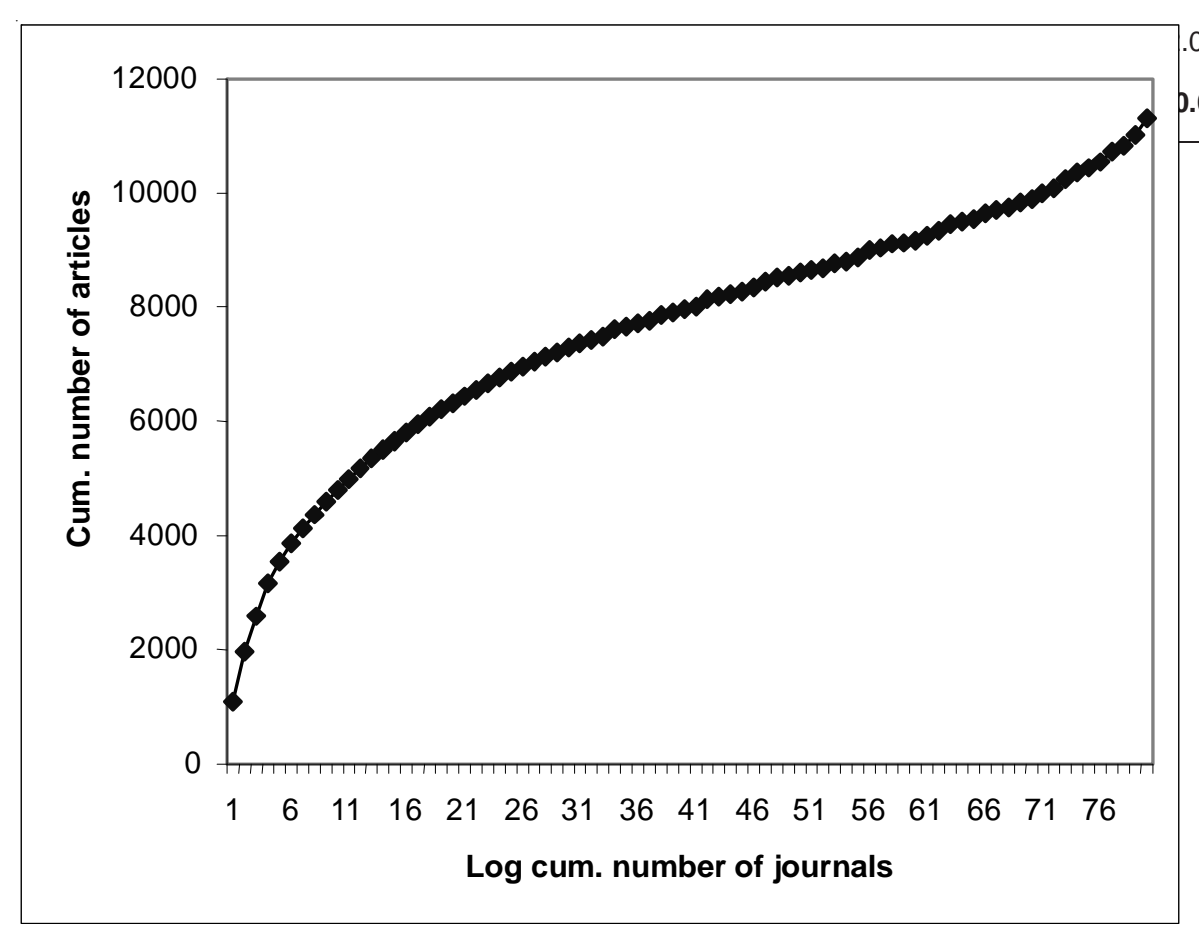

Figure 1. Bradford plot for journals distribution. 
first zone containing 4 journals contributed 3172 references, the 51 journals of second zone produced 5162 references and the 635 journals of third zone produced 2985 references. Here the mean value of the Bradford Multiplier (BM) is large, i.e., a two digit. The larger the BM, presumably, the higher is the scatter. Although the value of BM also depends on the size of the data, smaller the data, smaller the value of BM.

Since the percentage of error is very negligible, the Bradford's law fits very well in this data set. The study identified only 4 journals as the core/nucleus journals that were most cited by the researchers of IISc, out of the total of 690 journals. 28.02 per cent of the total citations of researchers of IISc, 51 journals 45.60 per cent, and the remaining 635 journals 26.37 per cent of citations. The three zones are not exactly the $1 / 3^{\text {rd }}$ of total citations as proved by Bradford. The first and third zones are more and the second zone is less than 33.33 per cent citations, and there is no exact match in the proportion of number of journals, nor an exact match in the number of papers of each group.

\subsection{Graphical Formulation}

The graphical formulation is just the experimental verification of the verbal formulation which observes certain regularity in the distribution of scientific publications.

The graph in the Figure 1 is logarithmic plot of the cumulative number of journal titles on the horizontal axis and the cumulative number of citations on the vertical axis. If the distribution confirms to Bradford's law, the graph is known as 'Bradford Bibliograph' and it will display the characteristics of 3 distinct regions: (i) a rapid rise for the first few points, (ii) a major portion of linear relation between two variables, and (iii) a 'droop' at the tail end of the distribution indicating the incompleteness of the bibliography ${ }^{45}$.

Figure 1 shows the Bradford bibliograph, where cumulative total of articles are plotted against logarithm of cumulative number of journals. On a Bradford bibliograph, the core journals are those whose points lay on the initial curved part of the graph until tangentially becomes a straight line. The sloping part at the top of the Bradford curve is called the groos droop. Brookes discussed the groos droop and argued that droop was an indication of the incomplete nature of the bibliography examined.

Bradford's verbal formulation of the law of scattering was not mathematically equivalent to the geometrical representation described in his article. The verbal form was the result of theoretical speculation while the graphical form was obtained from empirical data derived from the bibliographies. The graphical formulation has been found to be more accurate when compared with data and also more convenient to use.

\section{CONCLUSION}

The journal distribution pattern of the IISc doctoral theses does not fit the Bradford's distribution pattern, i.e., $1: n ; n^{2}$. When the multiplier for the first two zones were calculated, the Bradford's law could be modified as $1: n: 4.35 \mathrm{n}^{2}$ (where $n=5$ ) and this modification fits the Bradford Law for the data set. But when the mean value of multiplier is considered (13.4), this modified Bradford law does not fit the journal distribution, as the percentage of error is very high (68.66 per cent). When the Leimkuhler model is employed for the verification of Bradford's law, it is found that the law find valid for the data set. The percentage of error is found to be the most negligible ( 0.072 per cent). Bradford's Law of Scattering is an area where much work has been done. However, till now, no one has come out with a single model that fits fairly well to most of the data set.

\section{REFERENCES}

1. Summers, Edward G.A. Review and application of citation analysis methodology to reading research journal literature. J. Amer. Soc. Inf. Sci., 1984, 35(6), 332-43.

2. Bradford, S.C. Sources of information on specific subjects. Engineering, 1934, 137 (3550), 85-86.

3. Bradford, S.C. Documentation. Crosby Lockwood and Sons, London, 1948.

4. Mahapatra, Gayatri. Bibliometric studies in the Internet era. Indiana Publishing Co., New Delhi, 2009.

5. Vickery, Brian C. Bradford law of Scattering. Journal Documentation, 1948, 4(3), 198-203.

6. Kendall, M.G. The bibliography of operational research. Op. Res. Quart., 1960, 11 (1, 2), 31-36.

7. Wilkinson, E. A. Ambiguity of Bradford's Law. Journal Documentation, 1972, 28, 122-30.

8. Leimkuhler, Ferdinand F. The Bradford distribution. J. Doc.,1967, 23 (3), 197-207.

9. Brookes, Bertram C. Theory of Bradford's law. Journal Documentation, 1977, 33(3), 180-209.

10. Avramescu, A. Theoretical foundation of Bradford's law. Int. Forum Inf. Doc., 1980, 5, 15-22.

11. Oluic-Vukovic, Vesna. Bradford's distribution: From the classical bibliometric 'law' to the more general scholastic models. J. Amer. Soc. Inf. Sci., 1998, 48(9), 833-42. 
12. Locket, M.W. The Bradford distribution: A review of the literature 1934-1987. Lib. Inf. Sci. Res., 1989, 11(1), 21-36.

13. Qui, Liwen. An empirical examination of the existing model for Bradford's law. Inf. Proc. Manage., 1990, 26(5), 655-72.

14. Drott, Carl M. Bradford's law; theory, empiricism and the gaps between. Library Trends, 1981, 30(1), 4252.

15. Groos, Ole V. Bradford's law and the KeenanAtherton data. Amer. Doc., 1967, 18(1), 46.

16. Fairthrone, Robert A. Empirical hyperbolic distribution (Bradford-Zipf- Mandelbrot) for bibliometric description and prediction. Journal Documentation, 1969, 25(4), 319-43.

17. Asai, Isao. A general formulation of Bradford's distribution: the graph- oriented approach. J. Amer. Soc. Inf. Sci., 1981, 32(2), 113-19.

18. Egghe, Leo. The dual of Bradford's law. J. Amer. Soc. Inf. Sci., 1986, 37, 173-89.

19. Burrel, Quentin L. Modelling the Bradford's phenomenon. Journal Documentation, 1988, 44(1), 1-18.

20. Basu, Aparna. On theoretical foundation of Bradford's law. In Informetrics-91, edited by I.K. Ravichandra Rao. SRELS, Bangaluru, 1992. pp. 11824.

21. Basu, Aparna. Models of Bradford law as solutions of different equations. In. 5th International Conference of the International Society for Scientometric and Informetrics, edited by E.D. Michael Koening and Abraham Bookstein, 7-10 June 1995. pp. 53-62.

22. Egghe, Leo. Applications of the theory of Bradford's law to the calculation of Leimkuhler's law and the completion of bibliographies. J. Amer. Soc. Inf. Sci., 1990, 41(7), 480.

23. Egghe, Leo. A note on different Bradford multipliers. J. Amer. Soc. Inf. Sci., 1990, 41(3), 204-09.

24. Ravichandra Rao, I.K. An analysis of Bradford multipliers and a model to explain law of scattering. Scientometrics, 1998, 41(1-2), 93-100.

25. Wagner-Dobber, R. Two components of a casual explanation of Bradford's law. J. Inf. Sci., 1996, 22(2), 125-32.

26. Nicolaisen \& Hjorland. Practical potentials of Bradford's: A critical examination of the received view. Journal Documentation, 2007, 63(3), 359-77.
27. Sengupta, I.N. Recent growth of the literature of Biochemistry and change in ranking of periodicals. Journal Documentation, 1973, 29(2), 210-11.

28. Goffman, William \& Morris, Thomas G. Bradford's law and library acquisition. Nature, 1970, 226, 92223.

29. Arjun Lal \& Panda, Krishna C. Bradford's law and its application to bibliographical of Plant Pathology dissertations: An analytical approach. Lib. Sci. with a Slant to Doc. Inf. Stud., 1999, 36(3), 193-206.

30. Gupta, D.K. Application of Bradford's law to citation data of Ethiopian Medical Journal. Ann. Lib. Sci. Doc., 1991, 38(3), 85-98.

31. Lawani, S.M. Bradford' law and the literature of agriculture. Int. Lib. Rev., 1973, 5(3), 341-50.

32. Tyagi, A.K. Bradford' law and its application to study citation frequency of bibliographical data of Indian Journal of Physics. ILA Bulletin, 1986, 21(3-4), 9095.

33. Nweke, Ken M.C. Bradford's law and the journal titles cited by research scholars in zoology at the Ibadan University, Nigeria. IASLIC Bulletin, 1990, 18(5-6), 323-29.

34. Asundi, A.Y. \& Humayoon Kabir, S. Evolving criteria for identification and selection of core periodical in a subject: a case study on Indian Horticulture. Lib. Sc. with a Slant to Doc. Inf. Stud., 1996, 33(1), 7384.

35. Bandyopadhyay, Amit Kumar. Bradford's law in different discipline. Ann. Lib. Sci. Doc., 1999, 46(4), 133-38.

36. Shukla, M.C.; Saksena, S. \& Riswadkar, M.R. Application of Bradford's and Lotka' distribution to Bio-energy literature a study based on 10 abstracting services. Ann. Lib. Sci.Doc., 2001, 48(1), 3-80.

37. Gupta, B.M. \& Suresh Kumar. Citation analysis of Theoretical Population Genetic literature. Library Herald, 2001, 39(4), 208-26.

38. Garg, K.C. \& Lalitha Sharma. A study of R \& D indicator in Indian industry using Bradford' law. J. Sci. Ind. Res., 1994, 53, 81-87.

39. Brookes, Bertram C. Bradford's law and the bibliography of science. Nature, 1969, 224(5223), 953-56.

40. Brookes, Bertram C. The complete Bradford-Zipf bibliograph. Journal Documentation, 1969, 25(1), 5860. 
41. Leimkuhler, Ferdinand F. An exact formulation of Bradford's law. Journal Documentation, 1980, 36(4), 289.

42. Brookes, Bertram C. The Bradford's law: A new calculus for the social sciences? J. Amer. Soc. Inf. Sci., 1979, 30(4), 233-54.

43. Sudhier Pillai, K.G. Journal citations in Physics doctoral dissertation of Indian Institute of Science. Ann. Lib. Inf. Stud., 2007, 54(4), 177-84.

44. Cline, Gloria S. Application of Bradford's law to citation data. Coll. Res. Lib., 1981, 42(1), 9.

45. Brookes, B.C. Bradford's law and bibliography of science. Nature, 1969, 232 (5223), 955.

\section{About the Author}

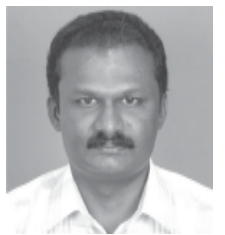

Dr K.G. Sudhier obtained his MSc (Physics) and BLISc from Aligarh Muslim University (AMU), Aligarh. He received his MLISc and PhD in Informetrics from the University of Kerala. After training in LPSC (ISRO), Trivandrum, he joined Govt Model Engineering College, Cochin as Librarian. He worked as Librarian in the Department of Communication and Journalism and Department of Geology, University of Kerala, Trivandrum also. He is an Academic Counsellor of Indira Gandhi National Open University (IGNOU) for its BLISc and MLISc programmes and Research Guide at the University of Kerala and M.S. University, Tirunelveli, Tamil Nadu. Presently, he is working as Lecturer in the Department of LIS, University of Kerala. He has published/ presented more than 25 research papers, both in national and international journals/conferences. He is a life member of ILA, IASLIC, KLA, MALA, SALIS and IALA. His research interests include citation analysis, scientometrics and digital libraries. 